\title{
Reliability of the connections used in IGBT modules, in aeronautical environment
}

\author{
A. Zéanh ${ }^{1,2,3,4, a}$, O. Dalverny ${ }^{2}$, M. Karama ${ }^{2}$, E. Woirgard ${ }^{3}$, S. Azzopardi ${ }^{3}$, A. Bouzourene ${ }^{1}$, J. Casutt $^{1}$ and \\ M. Mermet-Guyennet ${ }^{4}$ \\ 1 THALES Avionics Electrical Systems, 41 boulevard de la République, BP 53, 78401 Chatou, France \\ 2 ENI de Tarbes - LGP, 47, avenue d'Azereix, BP 1629, 65016 Tarbes Cedex, France \\ 3 Université Bordeaux - Laboratoire IMS, 351 cours de la Libération, 33405 Talence Cedex, France \\ 4 PEARL, Alstom Transport Tarbes, rue du Docteur Guinier, BP4, 65600 Séméac, France
}

Received 24 December 2007, accepted 26 March 2008

\begin{abstract}
In this paper, two IGBT modules assembling technologies with double side cooling capabilities and high level of integration were proposed for aeronautic applications after a state of the art and failures analysis. These technologies are compared using design of experiment based on non-linear finite element analysis with various materials, with respect to their potential failures under thermal and power loading profiles. The configurations optimizing the lifetime and reliability level were pointed out by loading profile and failure mode. Recommendations were then done in order to choose the optimal configuration of assembly for each application. Finally, these design rules were followed by the study of parts dimensions effects on the design outputs in order to help dimensioning the IGBT modules.
\end{abstract}

Key words: Power electronic packaging; constitutive laws; failures criteria; FEM; DoE.

\section{Introduction}

Within the framework of the electric plane programs which policy aims at replacing hydraulic actuators by electric ones for weight reduction and reliability improvement, the aircraft industry is facing a higher demand of electric power, fact which involves an increasing use of IGBT modules in power converters. Although such modules have been well studied and known in railway and the automotive domains, they will be subjected to stresses and operational cycles specific to the aeronautical environment. It was predicted that these modules will be used in harsh environment as in the engine nacelle, near the actuators they supply. Consequently, this requires manufacturers to answer some questions about their lifetime and reliability issues.

Many works studied solders lifetime [1] and evaluated modules reliability by probabilistic approaches [2], but the question of an optimal design for a specific application was usually studied by packaging techniques overviews.

The objective of this work is to propose specific technologies of IGBT modules, materials choice and mechanical dimensioning rules, for aeronautic applications.

To tackle this problem, the followed steps consist in analyzing the failures observed in railway and automotive environments, (wire bonding lift-off, solders crack, substrates delamination... ), in order to propose solutions

\footnotetext{
${ }^{a}$ Corresponding author: adrien.zeanh@enit.fr
}

concerning connection techniques and materials more appropriate to aeronautical operational environment. Two sandwich assemblies with ceramic substrates and metallizations, brazed on two base plates for double side cooling capabilities were proposed, with respect to aeronautic criteria.

These technologies were then compared with different materials chosen according their availability and in compliance with regulations about the use of hazardous substances [1].

In aeronautic applications, IGBT modules can be considered as operating under a combination of two loading profiles: a power loading at chips levels when switched at high frequency to ensure good input and output current waveforms, and a thermal loading due to environmental temperature variation.

For both profiles, Design of Experiments method was used basing on non-linear Finite Element Modelling results regarding the chips junction temperatures (thermal impedances), the chips and ceramic substrates brittle fracture (maximal principal stresses) and the critical solders joints fatigue (Inelastic Strain Energy Densities - ISED). A $2^{3}$ factorial design built according to the Yates algorithm helped reducing the number of simulations while getting the maximum information on how materials and their interactions affect the module design outputs. The most significant factors with their effects were pointed out for each yield response, and then recommendations were proposed. 


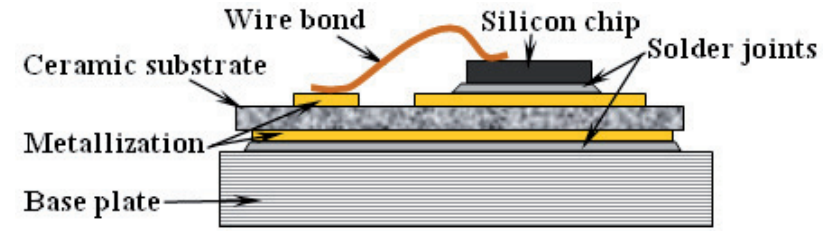

Fig. 1. Structure of a wire bonding IGBT module.

Then, an analysis was performed on module geometrical parameters (bumps sizes and layers thicknesses) to determine how they affect the yield responses. This second analysis brought additional information about the effect of these parameters design rules for each specific application.

\section{IGBT modules technologies overview}

For high power electronic applications, such as in power transmission, industrial drives, and locomotive traction control systems, many IGBT modules packaging approaches were proposed by industrials and research laboratories. The most common of these technologies are presented hereafter, with their main advantages and drawbacks.

\subsection{Wire bonding connection module}

This approach is the most used in IGBT module packaging. The chips are brazed on a metallized substrate and base plate, the electrical connections being achieved by wire bonds (Fig. 1). These wires bonds are main cause of failure under power cycling [3] as depicted in Figure 2. Large solder joints cracks (Fig. 3a) are main failures mode under thermal cycling [4]. As shown in Figure 3b, the delamination starts at solder joint corners, causing thermal impedance degradation and then chip excessive heat [5]. The substrates and silicon chips also exhibits high risk of brittle fracture. Other concerns with the use of this technology in aeronautical environment are about the worst electromagnetic compatibility due to high parasitic inductances, the poor thermal management and low integration level. Some other approaches were proposed.

\subsection{Pressure pack module}

Sandwich assembly with chips pressed between two attachments flanges with molybdenum interleaving part to accommodate the coefficients of thermal expansions (Fig. 5). This technology exhibits a good reliability because of the absence of solder joints, a good thermal management but needs special isolation and cooling systems, leading excessive weight and cost.

\subsection{Layer connection technologies}

This approach was first proposed in 2001 by General Electric [6], the chips are mounted on metallized substrate with top connections obtained by alternating conducing and dielectric layers (Fig. 6). Other variants of this technology are Planar Power Polymer Packaging (General Electric - 2004) and Embedded Power (CPES - 2004) [7]. Despite of the good electrical and thermal performances with high integration level, these approaches exhibit high parasitic capacitances and require complex and delicate manufacturing processes.

\subsection{Bump array contact modules}

This technology is based on chips brazed on metallized substrate, the connections being realized by solder bump arrays (Fig. 7). Many variants of this technology were proposed. The most known of this approach are Dimple Array Interconnexion (CPES - 2004) [6], Flip Chip on Flex (CPES, General Electric - 2004) [6] and Power Bump Connection (Eupec, PEARL - 2004). This approach presents a better integration level and thermal management compared to wire bonding technology, but requires complex and delicate manufacturing processes. Questions about lifetime of connection solders during thermal cycling also need to be answered.

\subsection{Direct solder contact module}

This approach first investigate in 2000 by INPG - LEG, CEA - LETI and Alstom Technology - PERT [8], aims at improving the thermal impedance and reliability by balancing the module structure [9]. The chips are sandwiched by two metallized substrates with connections by direct solder (Fig. 8). Despite of the good electrical and thermal performances with high integration level $[8,10]$, this technology needs designers to answer questions about dielectric withstand, because of the low distance between metallizations.

\section{Choice of IGBT modules configurations}

Selection criteria were defined on the basis of thermal and thermomechanical efficiency, (chips connection possibilities, integration level, thermal management, electromagnetic compatibility, weight, volume, materials safe operating areas and toxicities, cost, processing...). Two sandwich technologies with Power Bump (PB) (Fig. 9) and Direct Solder (DS) (Fig. 10) connection technique were retained. Both assemblies allow double side cooling with good integration levels.

\subsection{Potential failures modes}

From mechanical point of view, two main failures are susceptible to occur in these technologies: solder joints thermomechanical fatigue and brittle materials (ceramics and 

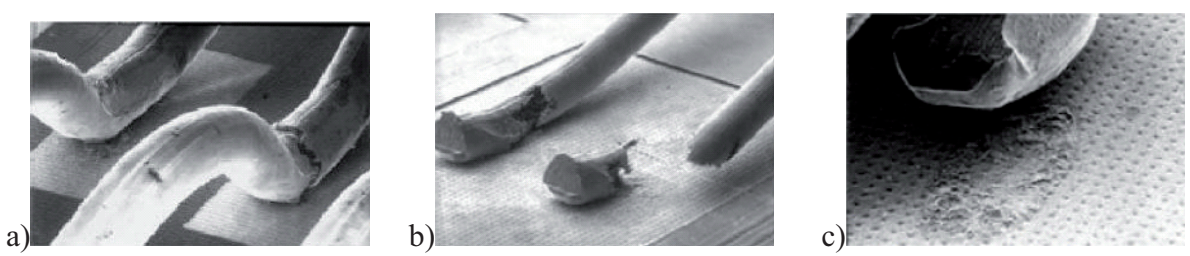

Fig. 2. Rupture (a), corrosion (b), and lift-off (c) of wire bonds [3]. 


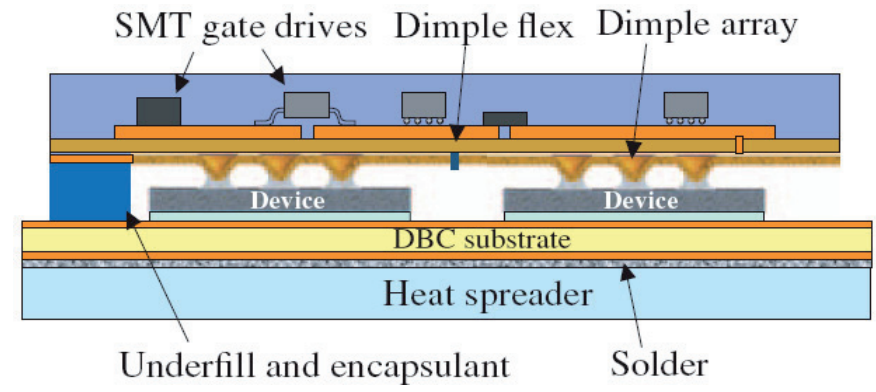

Fig. 7. Dimple array interconnexion (CPES - 2004).

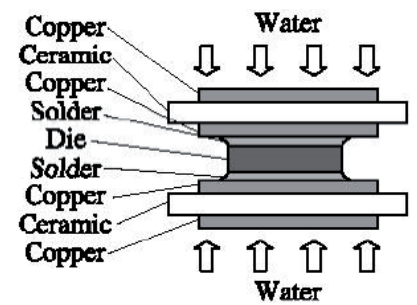

Fig. 8. Direct solder contact module [8].

Table 1. Base plates constitutive laws parameters $[4,12]$.

\begin{tabular}{lll}
\hline & $\mathrm{Al}-\mathrm{SiC}(63 \%)$ & $\mathrm{Cu}-\mathrm{C}(40)$ \\
\hline$\lambda(\mathrm{W} /(\mathrm{K} \mathrm{m}))$ & 175 & $300 / / 160 \perp$ \\
$\mathrm{C}\left(\mathrm{J} /\left(\mathrm{kg}{ }^{\circ} \mathrm{C}\right)\right)$ & 741 & 420 \\
$\rho\left(\mathrm{kg} / \mathrm{m}^{3}\right)$ & 4000 & 6100 \\
$\mathrm{CTE}\left(10^{-6} / \mathrm{K}\right)$ & 7.9 & 8.5 \\
$E(\mathrm{GPa})$ & 192 & 75 \\
$\nu$ & 0.24 & 0.3 \\
\hline
\end{tabular}

\section{Materials thermal and mechanical behaviour}

Thermal and mechanical properties were gathered from literature researches, for all the materials regarding their operating conditions, melting point, yield stress, Ultimate Tensile Strength (UTS), Coefficients of Thermal Expansion (CTE), etc.

\subsection{Ceramics and metallizations}

The base plates thicknesses lead stresses to remain in their elastic domains. Linear elastic law was used to model their mechanical behaviour. The corresponding material law parameters are presented in Table 1.

As suggested by Dupont in [4], elastoplastic law with linear kinematic hardening was used to model metallization mechanical behaviour. Table 2 shows the corresponding material parameters.

\subsection{Silicon chips and ceramic substrates}

Regarding the observed failures at their level, and their traditional operating conditions, these materials will be modelled with elastic linear law, with brittle fracture.
Table 2. Metallization constitutive laws parameters [4].

\begin{tabular}{lll}
\hline & Aluminium & Copper \\
\hline$\lambda(\mathrm{W} /(\mathrm{K} \mathrm{m}))$ & 220 & 398 \\
$\mathrm{C}\left(\mathrm{J} /\left(\mathrm{kg}^{\circ} \mathrm{C}\right)\right)$ & 880 & 380 \\
$\rho\left(\mathrm{kg} / \mathrm{m}^{3}\right)$ & 2700 & 8850 \\
$\mathrm{CTE}\left(10^{-6} / \mathrm{K}\right)$ & 24 & 17.3 \\
$E(\mathrm{GPa})$ & 70.6 & 128 \\
$\nu$ & 0.34 & 0.36 \\
Yield Stress $(\mathrm{MPa})$ & 17.8 & 98.7 \\
Tangent modulus $(\mathrm{MPa})$ & 350 & 1000 \\
\hline
\end{tabular}

Table 3. Chips and ceramics constitutive laws parameters [4].

\begin{tabular}{llll}
\hline & Silicon chip & AlN ceramic & $\begin{array}{l}\mathrm{Si}_{3} \mathbf{N}_{4} \\
\text { ceramic }\end{array}$ \\
\hline$\lambda(\mathrm{W} /(\mathrm{K} \cdot \mathrm{m}))$ & 146 & 190 & 60 \\
$C\left(\mathrm{~J} /\left(\mathrm{kg} \cdot{ }^{\circ} \mathrm{C}\right)\right)$ & 750 & 750 & 800 \\
$\rho\left(\mathrm{kg} / \mathrm{m}^{3}\right)$ & 2330 & 3300 & 3290 \\
$\mathrm{CTE}\left(10^{-6} / \mathrm{K}\right)$ & 2.5 & 4.5 & 3.3 \\
$E(\mathrm{GPa})$ & 130 & 344 & 310 \\
$\nu$ & 0.22 & 0.25 & 0.27 \\
$\mathrm{UTS}(\mathrm{MPa})$ & 200 & 400 & 800 \\
\hline
\end{tabular}

Many models based on weakest link theory were proposed to describe the ceramics rupture [13]. These approaches need the material parameters to be identified, but a more simple way is to consider the Rankine's (maximal principal stress) criterion which is widely sufficient within a comparison purpose. The corresponding material parameters are given in Table 3.

\subsection{Solders joints}

The solders, operating at temperatures above the third of their melting points, were described using Anand's unified viscoplastic model [14].

This law was not available in ABAQUS ${ }^{T M}$ Software, it was integrated according to the steps suggested by [15], and implemented via the user interface UMAT. A FORTRAN subroutine, calculating the stress increment and material Jacobian matrix, knowing the strain field, was written. Simulations and verifications with various solders revealed that there are good agreements between the user subroutine and bibliography results presented in $[16,17]$. Table 4 lists hereafter the two solders constitutive laws parameters.

Concerning the solders fatigue, inelastic dissipation is believed to better capture the accumulated damage. Many authors proposed cyclic Inelastic Strain Energy Density (ISED) based models for solders joints lifetime prediction $[1,18]$. These models show that the number of loading cycles before solder failure is a monotonic decreasing function of the ISED dissipated per cycle. The analysis of the various assembling configurations is for this reason done hereafter according to the ISED dissipated in solder joints per loading cycle. 

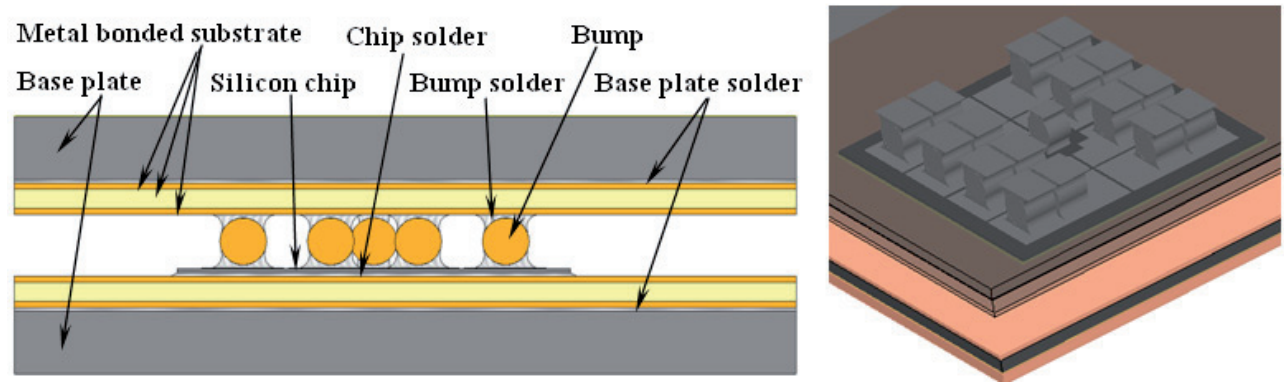

Fig. 9. Power Bump (PB) assembly (Infineon 1200 V - 150 A chip).
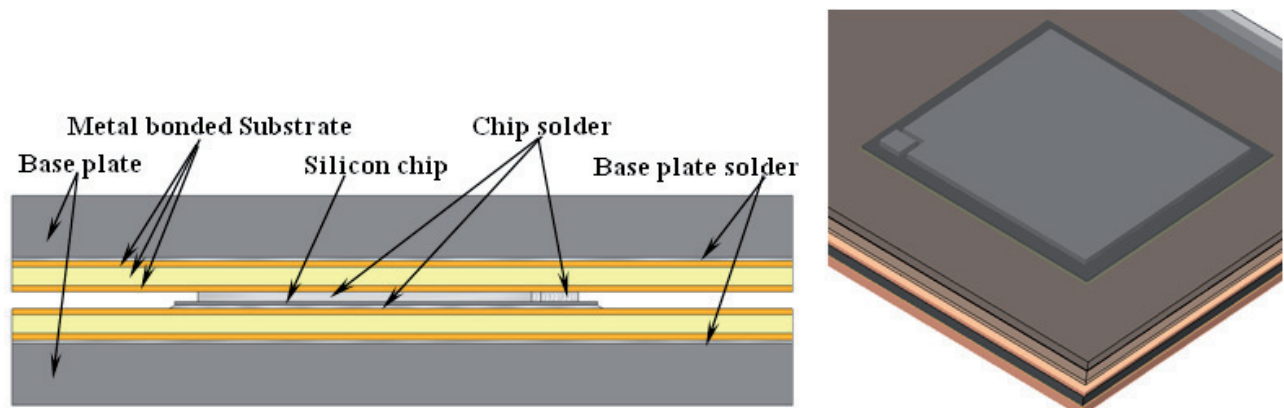

Fig. 10. Direct Solder (DS) assembly (ABB $1200 \mathrm{~V}-150$ A chip).

Table 4. Solders constitutive laws parameters [16,17].

\begin{tabular}{lll}
\hline & $\mathrm{Pb}_{29.5} \mathrm{Sn}_{5} \mathrm{Ag}_{2.5}$ & $\mathrm{Sn}_{96.5} \mathrm{Ag}_{3.5}$ \\
\hline$\lambda(\mathrm{W} /(\mathrm{K} \mathrm{m}))$ & 35 & 33 \\
$C\left(\mathrm{~J} /\left(\mathrm{kg}{ }^{\circ} \mathrm{C}\right)\right)$ & 129 & 200 \\
$\rho\left(\mathrm{kg} / \mathrm{m}^{3}\right)$ & 11300 & 7360 \\
$\mathrm{CTE}\left(10^{-6} / \mathrm{K}\right)$ & 29 & 30.2 \\
$E(\mathrm{MPa})$ & $24028-28 \cdot T\left({ }^{\circ} \mathrm{C}\right)$ & $47200-191 \cdot T\left({ }^{\circ} \mathrm{C}\right)$ \\
$\nu$ & 0.44 & 0.4 \\
\hline \multicolumn{3}{l}{ Anand's Parameters } \\
\hline$s_{0}(\mathrm{MPa})$ & 33.07 & 7.72 \\
$Q / R(\mathrm{~K})$ & 11024 & 14100 \\
$\mathrm{~A}(\mathrm{~s}-1)$ & 105000 & 1630000 \\
$\xi$ & 7 & 1.61 \\
$m$ & 0.241 & 0.13 \\
$h_{0}(\mathrm{MPa})$ & 1432 & 58700 \\
$\hat{s}(\mathrm{MPa})$ & 41.63 & 11.99 \\
$n$ & 0.002 & 0.017 \\
$a$ & 1.3 & 2.09 \\
\hline
\end{tabular}

\section{Numerical design of experiment}

With respect to the potential failure modes and loading profiles, nine design responses were defined and considered for this analysis: thermal impedances for chips junction temperatures, maximal principal stresses for chips and ceramic substrates brittle fracture, and the inelastic strain energy densities for critical solders joints fatigue, for both loadings profiles. Table 5 lists the responses considered, with their given labels.

The nine plans was built following the Yates algorithm [19], 3 factors listed in Table 6, with 2 levels each other, were considered with their first order interactions.
The responses calculations were performed with the nonlinear finite element models presented below.

\subsection{Finite element modelling}

Two parameterised finite element models (Fig. 11) generated using python scripts under ABAQUS ${ }^{\mathrm{TM}}$ were used. The geometries of the elementary modules are based on standard thicknesses used in automotive and railway domains: base plates $(3 \mathrm{~mm})$, ceramic substrates $(635 \mu \mathrm{m})$ metallizations $(300 \mu \mathrm{m})$, base plate solder joints $(100 \mu \mathrm{m})$ bumps cylinders $(\phi 1.4 \mathrm{~mm} \times 1.5 \mathrm{~mm})$ and direct connection solder joints $(200 \mu \mathrm{m})$.

Three-dimensional solid linear brick and tetrahedron elements were used for meshing the geometry, the interfaces being supposed perfect.

As suggested by Guédon-Gracia et al. in [20], the assembling process and storage were simulated for the various configurations in order to compute residual stresses across the whole assemblies before cycling. The two loading profiles considered are presented below.

\subsubsection{Power cycling}

To model the power cycling, $250 \mathrm{~W}$ heat dissipation was generated in the whole volume of the IGBT chip within relative short cycles as shown in Figure 12. An overall heat transfer coefficient corresponding to water cooling, at $70^{\circ} \mathrm{C}$ reference temperature was applied on the two external sides of the base plates as boundary conditions. 
Table 5. DoE responses definition.

\begin{tabular}{cl}
\hline & \multicolumn{1}{c}{ Responses } \\
\hline$Y 1$ & Thermal impedance \\
$Y 2$ & Base plate solder cyclic ISED under thermal cycling \\
$Y 3$ & Chip solder cyclic ISED under thermal cycling \\
$Y 4$ & Substrate stress ratio (max. stress/UTS) under thermal cycling \\
$Y 5$ & Chip stress ratio (max. stress/UTS) under thermal cycling \\
$Y 6$ & Base plate solder cyclic ISED under power cycling \\
$Y 7$ & Chip solder cyclic ISED under power cycling \\
$Y 8$ & Substrate stress ratio (max. stress/UTS) under power cycling \\
$Y 9$ & Chip stress ratio (max. stress/UTS) under power cycling \\
\hline
\end{tabular}

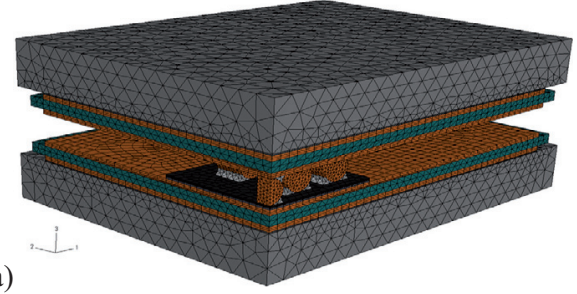

b)

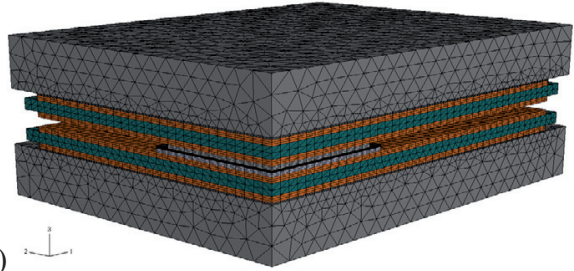

Fig. 11. Elementary power bump (a) and direct solder (b) modules finite elements models.

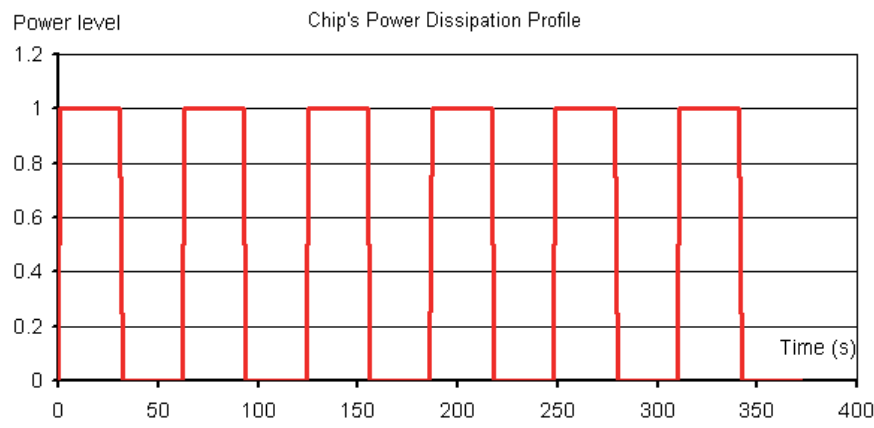

Fig. 12. Power cycling profile.

Table 6. DoE factors and levels.

\begin{tabular}{llll}
\hline & \multirow{2}{*}{ Factors } & \multicolumn{2}{c}{ Levels } \\
\cline { 2 - 4 } & & \multicolumn{1}{c}{1} & \multicolumn{1}{c}{1} \\
\hline A & Connection & PB & DS \\
B & Metallization & Copper & Aluminium \\
C & Ceramic Substrate & $\mathrm{Si}_{3} \mathrm{~N}_{4}$ & AlN \\
\hline
\end{tabular}

\subsubsection{Thermal cycling}

The International Standard of Atmosphere (ISA) gives the aircraft external temperature profile during a flight cycle. To represent these loadings, an accelerated thermal profile defined according to the Military Standard Handbook $883 \mathrm{~F}$ was considered.

As depicted in Figure 13, the profile starts at $25^{\circ} \mathrm{C}$, the ramp rate was $20^{\circ} \mathrm{C} / \mathrm{min}$ and the dwell time at $-55^{\circ} \mathrm{C}$ and $125^{\circ} \mathrm{C}$ was $20 \mathrm{~min}$.

\subsection{Simulation results}

The heat flux balance across assemblies and the thermal impedances were evaluated from the power cycling simu-

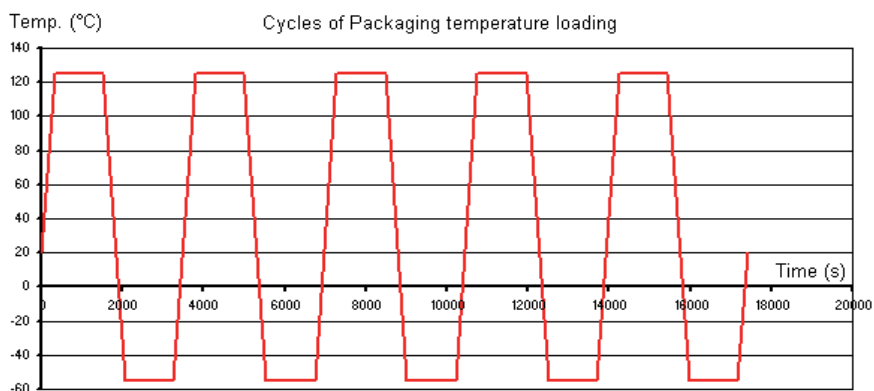

Fig. 13. Thermal cycling profile.

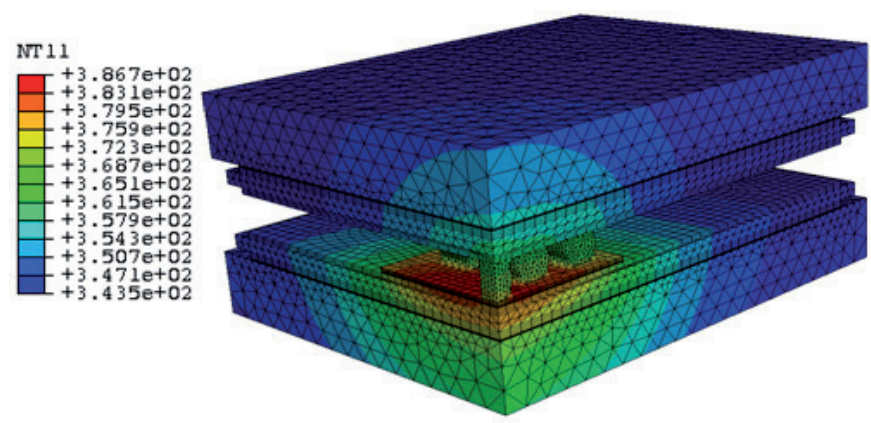

Fig. 14. Temperature distribution in solder bump assembly $(\mathrm{K})$.

lations (Fig. 14). The thermal impedances $(Y 1)$ were calculated from the chip maximal temperatures, measured after the steady state is reached. For all the configurations, the design responses $Y 4, Y 5, Y 8$ and $Y 9$ were computed by the ratio of maximal principal stresses in the ceramic substrates (Fig. 15) and chips (Figs. 16 and 17), over their mechanical strengths.

The maximal principal stress in the ceramic substrate is localized at the periphery of the bonded metallization. 

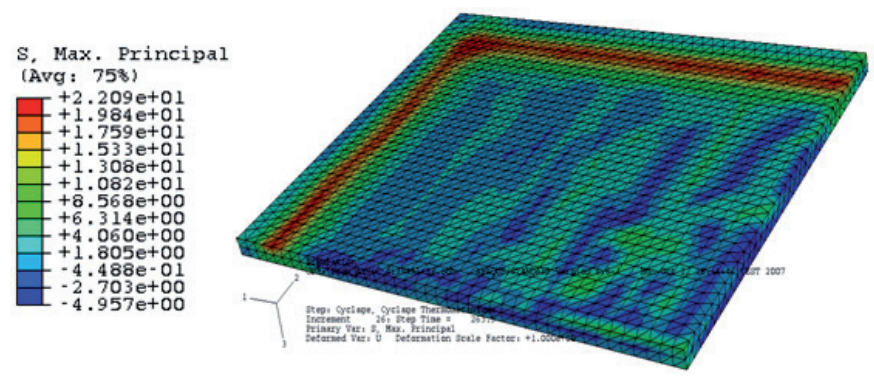

Fig. 15. Maximal principal stress distribution in ceramic substrate $(\mathrm{MPa})$.

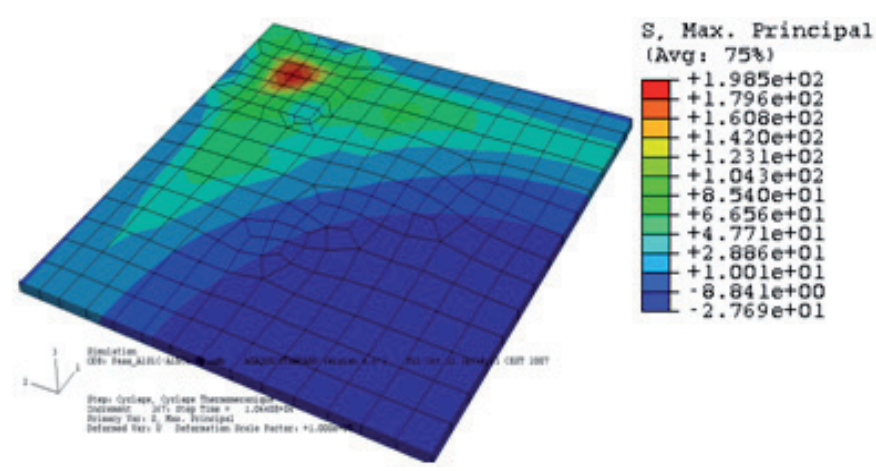

Fig. 16. Maximal principal stress distribution in silicon chip with DS connection (MPa).

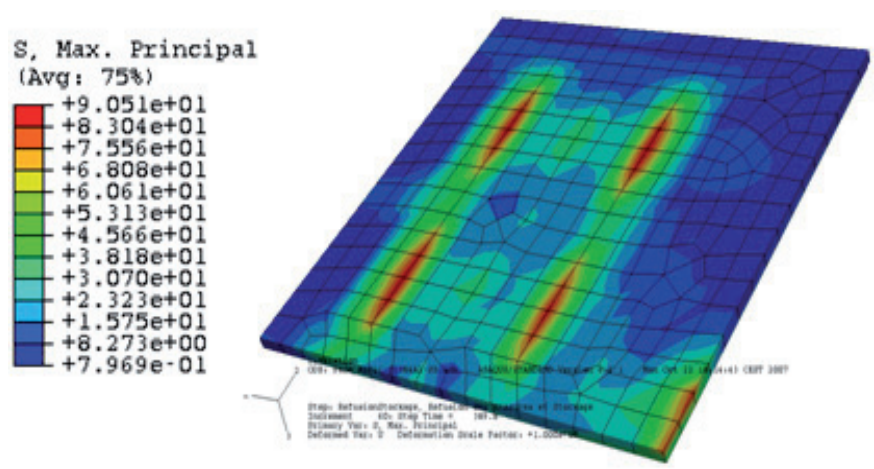

Fig. 17. Maximal principal stress distribution in silicon chip with $\mathrm{PB}$ connection $(\mathrm{MPa})$.

In the chips, the maximal principal stress were localized around bump contacts for solder bump connection (Fig. 16) and just under the gate for direct solder connection (Fig. 17).

In order to evaluate $Y 2, Y 3, Y 6$ and $Y 7$, inelastic strain energy densities were computed over the solder joints (Figs. 18-20). Many works [5] showed that the crack in large area solders propagates from solder joint corner (Fig. 3b). The ISED distribution in base plate solder (Fig. 18) is consistent with this result, and then, for more accuracy in this analysis, $Y 2$ and $Y 6$ were evaluated in the corner elements instead of the whole solder joint.

Regarding connection solders, the ISED were found to be maximal in the bump solder in solder bump assemblies (Fig. 19) and in the gate solder for direct solder assemblies

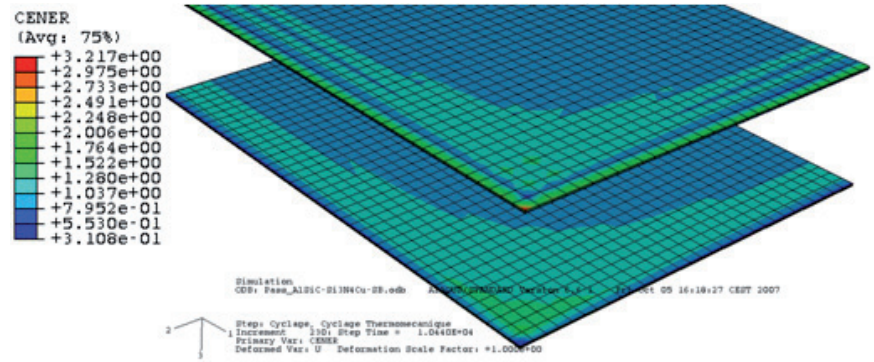

Fig. 18. ISED distribution in base plate solder after thermal cycling $\left(\mathrm{mJ} / \mathrm{mm}^{3}\right)$.

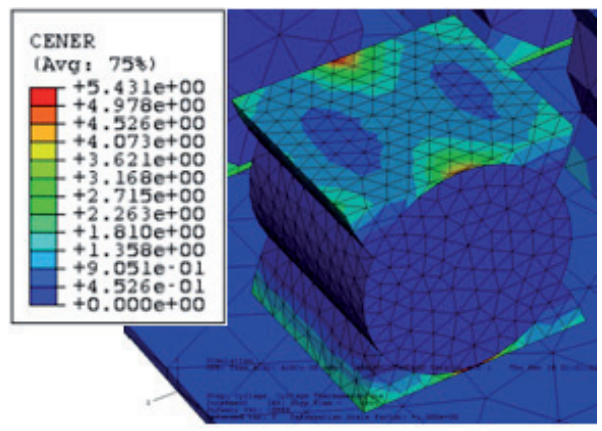

Fig. 19. ISED distribution in bumps solder after thermal cycling $\left(\mathrm{mJ} / \mathrm{mm}^{3}\right)$.

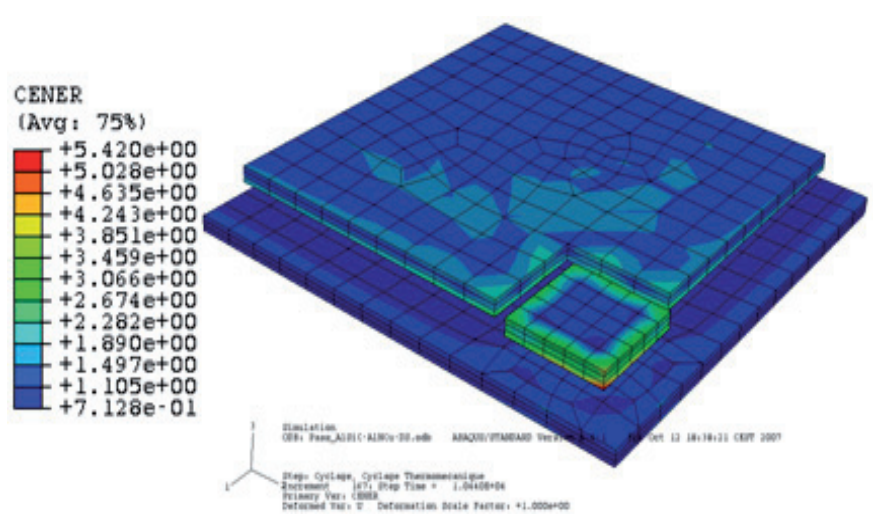

Fig. 20. ISED distribution in direct connection solder after thermal cycling $\left(\mathrm{mJ} / \mathrm{mm}^{3}\right)$.

(Fig. 20). Due to the relative small size of these solders, $Y 3$ and $Y 7$ were evaluated in their whole volume.

As observed in Figure 21, the inelastic strain energy density accumulation per cycle, quickly reaches a saturated value within three loading cycles. This observation allows reducing the computation time, by calculating $Y 2$, $Y 3, Y 6$ and $Y 7$ within the third cycle, while having good accuracy on the results.

\subsection{DoE results and analysis}

Basing on simulation results, the effects of the factors were evaluated for the nine responses. A student test with a risk of $5 \%$ helped identifying the most significant factors for the nine models. All the 9 responses models built 

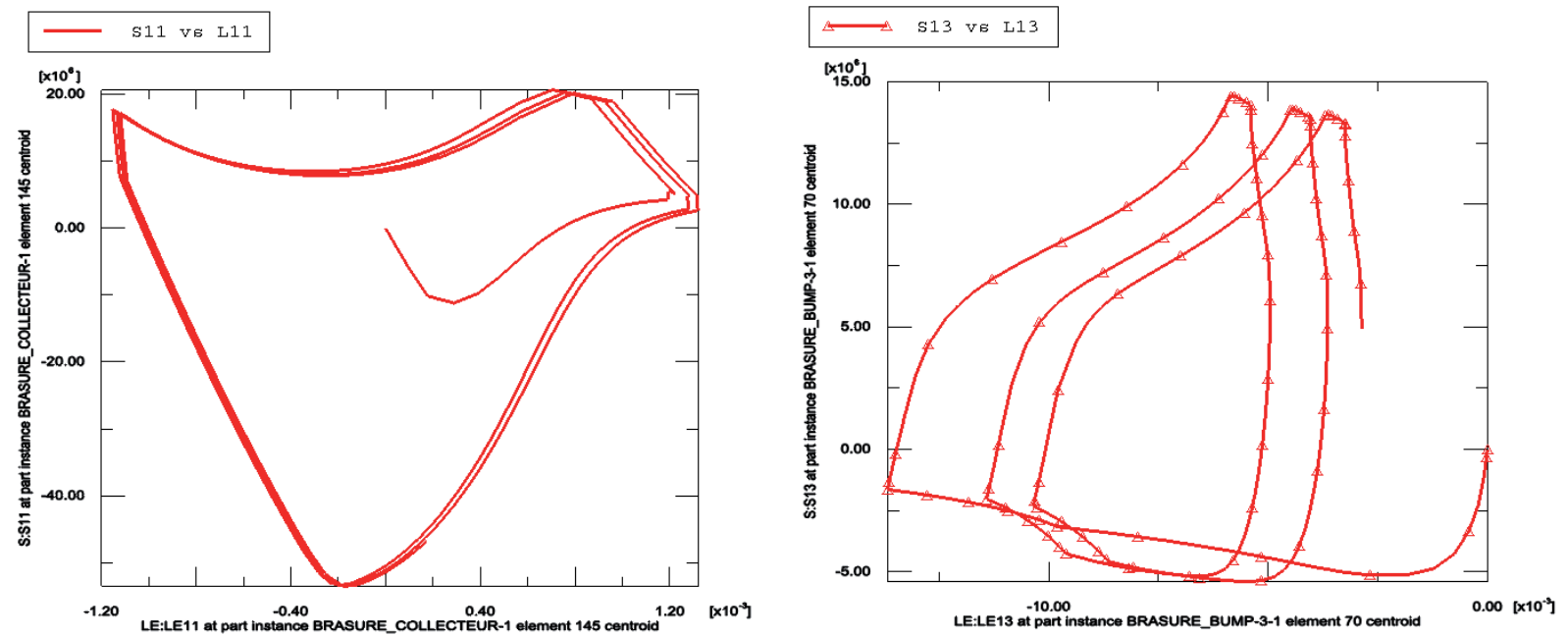

Fig. 21. Normal and shear stress versus strain, during thermal cycling without residual stresses computation.

with the identified factors passed successfully a FischerSnedecor test with a $5 \%$ risk. Table 7 sums these results, with the significant effects highlighted in bold.

The assembling configurations minimising the design responses, and therefore maximising the modules lifetimes and reliabilities were then identified with respect to the loading profiles.

\subsubsection{Thermal impedance and fluxes balance}

It appears that the three factors are significant, without their interactions. Direct solder connection with AlN substrate and copper metallization should be preferred, but considering the intrinsic contribution of the metallization within the thermal impedance model (4.6\%), aluminium could be an excellent alternative. The fluxes should be more balanced across the assemblies in order to minimize thermal stress concentrations. Regarding this characteristic, direct solders assemblies are superior with $47 \%$ of thermal flux balance through bottom and 53\% through top cooling faces, compared to solder bump ones which lead to a partition of $26-74 \%$. Other simulation with the two base plates showed that $\mathrm{Cu}-\mathrm{C}$ is superiors than $\mathrm{Al}-$ $\mathrm{SiC}$ with about $6.3 \%$ of thermal impedance improvement.

\subsubsection{Base plates solder fatigue}

The only significant factors are the ceramics and metallizations. The use of AlN substrate with aluminium metallization reduces significantly the inelastic strain energy density for both loading profiles. Regarding base plates, $\mathrm{Cu}-\mathrm{C}$ are superiors than $\mathrm{Al}-\mathrm{SiC}$ in power cycling, due to their better thermal performances, but less interesting in thermal cycling because of higher coefficient of thermal expansion.

\subsubsection{Chip connections solder fatigue}

Only aluminium metallizations are recommended for thermal cycling. Considering power cycling loading, direct solder connection, AlN substrate with copper metallization should be recommended.

\subsubsection{Ceramic fracture}

The stress ratio in the ceramic only depends on the metallization and the ceramic substrate for both loading profiles. Aluminium and $\mathrm{Si}_{3} \mathrm{~N}_{4}$ ceramic minimises ceramic cracking failures risk.

\subsubsection{Chip fracture}

During thermal cycling, the recommendations are direct solder connection, AlN substrate with aluminium metallization. None of the factors considered have not significant effects on chips stresses during power cycling.

\subsection{Discussion}

Some contradiction appears in the above analysis when trying to take into account the recommendations for all the responses and loading profiles together. To solve these contradictions, the materials choices could be done with respect to the most critical design outputs and the most preponderant profile, knowing that IGBT modules really operate under a combination of thermal and power loadings. The significant effects presented in Table 7 could then help doing the appropriate design.

The direct solder connection assembly with aluminium bonded AlN appears as the most consensual configuration.

A good solution could be the use of AlN substrate with copper bonded at the chip side and aluminium bonded at base plate side, with suitable thicknesses in order to avoid substrates fracture by bimetallic effect. 
Table 7. DoE effects and significance test results.

\begin{tabular}{cccccccc}
\hline Responses & $I$ & $\mathrm{~A}$ & $\mathrm{~B}$ & $\mathrm{C}$ & $\mathrm{AB}$ & $\mathrm{AC}$ & $\mathrm{BC}$ \\
\hline$Y 1$ & 0.152 & -0.031 & 0.007 & -0.013 & -0.002 & 0.003 & -0.001 \\
$Y 2$ & 471749 & 1927 & -14631 & -16313 & -2083 & -342 & 2487 \\
$Y 3$ & 319290 & 27350 & -51018 & -13670 & 4212 & -278 & -2644 \\
$Y 4$ & 0.138 & 0.005 & -0.046 & 0.040 & 0.008 & 0.001 & -0.018 \\
$Y 5$ & 0.621 & -0.054 & -0.006 & -0.046 & -0.047 & -0.006 & 0.005 \\
$Y 6$ & 31656 & -713 & -29262 & -7259 & 821 & 861 & 6989 \\
$Y 7$ & 15983 & -7660 & 2198 & -4235 & -855 & 1775 & -418 \\
$Y 8$ & 0.109 & 0.001 & -0.029 & 0.032 & -0.004 & -0.001 & -0.008 \\
$Y 9$ & 0.399 & -0.035 & -0.037 & -0.040 & -0.078 & -0.034 & -0.012 \\
\hline
\end{tabular}

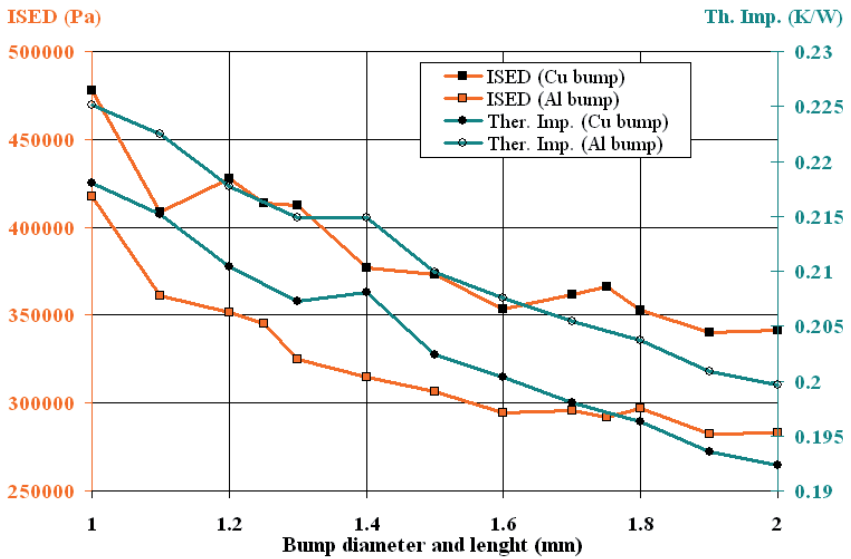

Fig. 22. Evolution of bump solders ISED and module thermal impedance with bump size and material.

\section{Influence of geometric parameters on module lifetime}

The objective of this study is to investigate how the thicknesses of base plate solder, metallizations, ceramic substrates, direct connection solder and bumps dimensions affect the module lifetime. For this purpose, different parameterized models with four IGBT chips, AlN substrates and $\mathrm{Al}-\mathrm{SiC}$ base plates were generated under $\mathrm{ABAQUS}^{T M}$ using python scripts. The results are presented here after.

\subsection{Bump nature and sizes}

The design parameters chosen for sizing the bumps were the module thermal impedance and the bump solders fatigue. Two materials (cooper and aluminium) were considered with sizes (diameter and length) varying from 1 to $2 \mathrm{~mm}$. Figure 22 presents the evolution of two design parameters for the two kinds of bump. It appears that the module thermal impedance and bumps solder cyclic ISED decrease with the bump size. Moreover, the use of aluminium bump instead of copper reduces bump solders cyclic ISED of about $18 \%$ while increasing the thermal impedance of about $3.6 \%$.

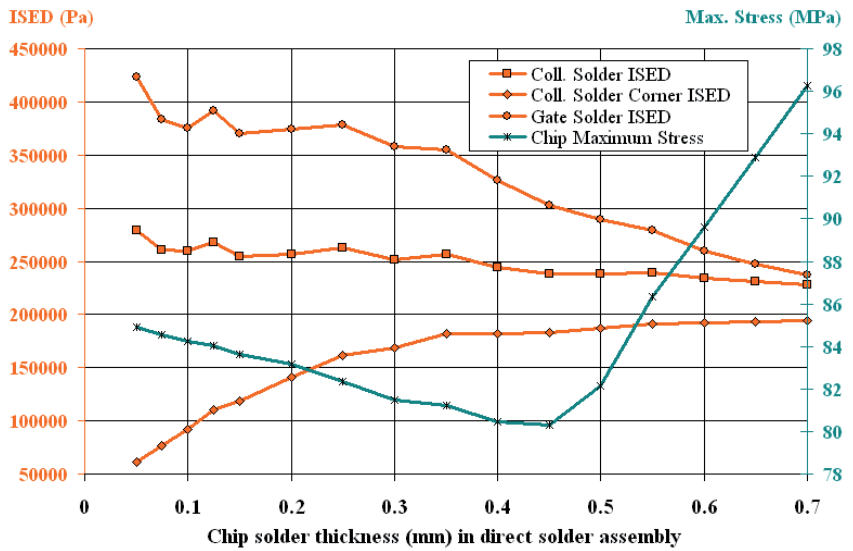

Fig. 23. Evolution of direct connection solders ISED and chip maximal principal stress with chip solder joint thickness.

\subsection{Direct connection solder thickness}

The design parameters chosen for sizing the solder thickness were the module thermal impedance, the chip maximal stress and the solder joints fatigue. The simulations were done with thicknesses varying from 50 to $700 \mu \mathrm{m}$. As presented in Figure 23, the inelastic strain energy density seems to be constant in the whole chip solder joint, while increasing in the corners. The gate solder joint which is the most critical, decreases with the solder thickness. The chip maximal principal stress presents a minimum for a solder joint thickness around $0.45 \mathrm{~mm}$, but the module thermal impedance increases with a rate of about $0.132 \mathrm{~K} /(\mathrm{W} \mathrm{mm})$.

\subsection{Base plate solder thickness}

The design parameters chosen for sizing the base plate solder thickness were the module thermal impedance and the base plate solders fatigue. The simulations were done with thicknesses varying from 20 to $300 \mu \mathrm{m}$. Figure 24 presents the evolution of the two design parameters considered. The thermal impedance increases linearly with a rate of $0.122 \mathrm{~K} /(\mathrm{W} \mathrm{mm})$, while the cyclic ISED seems to be constant when calculated in the whole solder joint, but quickly decreases at the corners until $0.1 \mathrm{~mm}$ before decreasing linearly with a rate of about $187000 \mathrm{~Pa} / \mathrm{mm}$. 


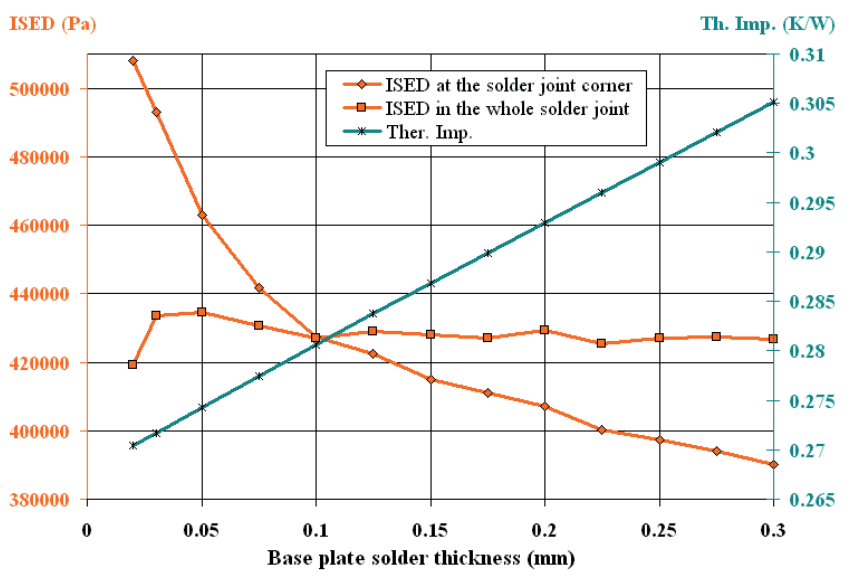

Fig. 24. Evolution of base plate solder ISED and module thermal impedance with base plate solder thickness.

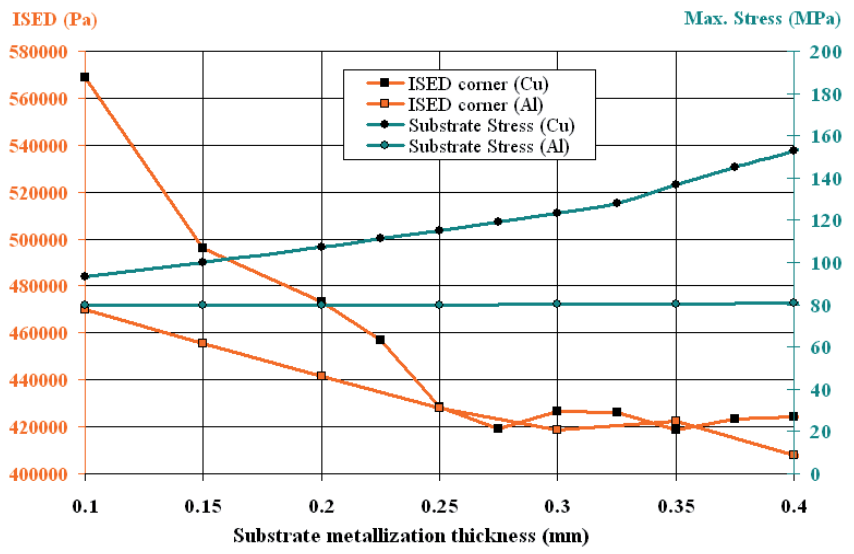

Fig. 25. Evolution of base plate solder corner ISED and substrate maximal principal stress with metallization nature and thickness.

\subsection{Metallization nature and thickness}

The design parameters chosen for sizing the metallization thickness were the module thermal impedance, the substrate maximal stress and the base plate solders fatigue. Two materials (cooper and aluminium) were considered, the simulations being done with thicknesses varying from 100 to $500 \mu \mathrm{m}$. Figure 25 presents the evolution of cyclic ISED at the corner of base plate solder joint. The maximal principal stress in the substrate seems to be constant with aluminium metallization, but increases linearly with copper metallization with a rate of about $150 \mathrm{MPa} / \mathrm{mm}$. Regarding the module thermal impedance, it evolves linearly, with a rate of $0.004 \mathrm{~K} /(\mathrm{W} \mathrm{mm})$ for aluminium and $-0.037 \mathrm{~K} /(\mathrm{W} \mathrm{mm})$ for copper metallization.

\subsection{Substrate thickness}

The design parameters chosen for sizing the substrate thickness were the module thermal impedance, the substrate maximal stress and the base plate solders fatigue. The simulations were done with thicknesses varying from 200 to $1400 \mu \mathrm{m}$. The maximal principal stress in the ceramic decreases with the substrate thickness (Fig. 26),

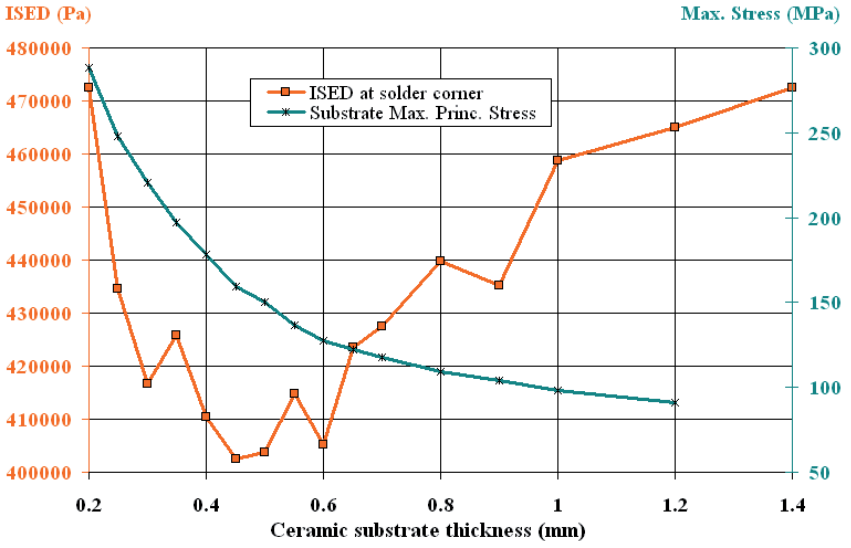

Fig. 26. Evolution of base plate solder corner ISED substrate maximal principal stress with substrate thickness.

while the thermal impedance increases linearly with a rate of about $0.013 \mathrm{~K} /(\mathrm{W} \mathrm{mm})$. Regarding the base plate solder corner cyclic ISED, the simulations done here with a $300 \mu \mathrm{m}$ copper metallized AlN substrate showed an optimum of substrate thickness between 0.4 and $0.6 \mathrm{~mm}$. Additional simulations could be necessary for each specific application in order to determine the ceramic optimal thickness, with respect to the metallization material and thickness.

\section{Conclusion}

The objective of this study was to propose IGBT modules technologies based on materials available today, and propose design rules to optimise the lifetime for aeronautic applications. FEM based DoE was done with respect to the main failure modes under thermal and power cycling loading profiles.

This work showed that there was not optimal configuration of assembly (connection techniques, materials and dimensions) for all the applications, the designer should then take into account the most representative profile with the most critical design parameters to define the module. To do this, the results presented in this paper could be very helpful. It is obvious that complementary simulations could be necessary for each specific application in order to verify the interactions between all the parameters.

Five configurations are being manufactured for thermal and power cycling tests, in order to verify the predicted thermomechanical performances and failures criteria.

\section{References}

1. A. Guédon-Gracia, Contribution à la conception thermomécanique optimisée d'assemblages sans plomb, Ph.D. Thesis of Université Bordeaux 1, France (2006)

2. A. Micol, M. Karama, O. Dalverny, C. Martin, M. Mermet-Guyennet, Reliability Design of Power Modules Using Probabilistic Approaches, Proc. of the 8th Conf. on 
Computational Structures Technology (12-15 September, 2006)

3. M. Ciappa. Microelectronics Reliability 42, 653-667 (2002)

4. L. Dupont, Contribution à l'étude de la durée de vie des assemblages de puissance dans des environnements haute température et avec des cycles thermiques de grande amplitude, Ph.D. Thesis of ENS Cachan - France (June 2006)

5. T. Lhommeau, C. Martin, M. Karama, R. Meuret, M. Mermet-Guyennet, Base-plate solder reliability study of IGBT modules for aeronautical Application, Proc. of EPE (Aalborg, 2007)

6. F.C. Lee, J.D. van Wyk, D. Boroyevich, G.Q. Lu, Z. Liang, P. Barbosa. IEEE Circuits and Systems Magazine 2, 4-23 (2002)

7. S. Dieckerhoff, Thermal performance and advanced power electronics packages, ECPE Seminar (Nürnberg, November 09, 2006)

8. C. Gillot, C. Schaeffer, C. Massit, L. Meysenc. IEEE Transactions on Components and Packaging Technologies $24(2001)$

9. J.G. Bai, J.N. Calata, G.Q. Lu, Comparative Thermal and Thermomechanical Analyses of Solder-Bump and DirectSolder Bonded Power Device Packages Having DoubleSided Cooling Capability, IEEE 0-7803-8269 (February 2004)

10. C.M. Johnson, C. Buttay, S.J. Rashidt, F. Udreat, G.A.J. Amaratungat, P. Ireland, R.K. Malhan, Compact Double-Side Liquid-Impingement-Cooled Integrated Power
Electronic Module, Proceedings of the 19th International Symposium on Power Semiconductor Devices \& ICs (Jeju, Korea, May 27-30, 2007)

11. European parliament directives concerning the use of hazardous substances http://ec.europa/environment/index_en.htm

12. J.F. Silvain, J. Soccart, Copper matrix composite materials used for thermal management of high power electronic devices, Imaps France (La Rochelle, 2006)

13. L.J.M.G. Dortmans, G. de With. J. Eur. Ceramic Soc. 6, $369(1990)$

14. G.Z. Wang, Z.N. Cheng, K. Beker, J. Wilde. Journal of Electronic Packaging 123 (2001)

15. A.M. Lush, G. Weber, L. Anand. Int. J. Plasticity 5, 521 (1989)

16. M. Pei, J. Qu, Constitutive Modeling of Lead-Free Solders, School of Mechanical Engineering, Georgia Institute of Technology, 0-7803-9085 - IEEE (July 2005)

17. J. Wilde, K. Becker, M. Thoben, W. Blum, T. Jupitz, G. Wang, Z.N. Cheng. IEEE Transactions on Advanced Packaging 23 (2000)

18. R. Darveaux, Effect of Simulation Methodology on Solder Joint Crack Growth Correlation, 50th Electronic Components and Technology Conference (2000)

19. M. Pillet, Les plans d'expériences par la méthode Taguchi (Les Éditions d'Organisation, Paris, 1997)

20. A. Guédon-Gracia, P. Roux, E. Woirgard, C. Zardini. Microelectronics Reliability 44, 1331 (2004) 